\title{
KANDUNGAN KADMIUM DI DALAM WORTEL, BAWANG PREI DAN BUNCIS \\ YANG DITANAM PADA TANAH BERBAHAN INDUK KAPUR DAN \\ VOLKANIK DENGAN DOSIS PUPUK P YANG BERBEDA
}

\author{
Charly Mutiara \\ mutiaracharly@ymail.com
}

\begin{abstract}
This study aims at investigating the content of cadmium on carrots, leeks, and stringbean grown on limestone and volcanic soil with different dose of $\mathrm{P}$ Fertilizer and comparing thecontents with cadmium content standardized by FAO/WHO.

This pot test employed random block design and was a factorial test with three factors, namely factor of plant species, soil type, and fertilizer dose with three repeated test. The levelsof each factor are plants species consisting of Carrot $(\mathrm{C} 1)$, leek $(\mathrm{C} 2)$, and stringbean (C3); soil type comprises of Andosol Nduaria (S1), MollisolFatumnasi (S2), VertisolOesao (S3) and MollisolBaumata (S4) and the fertilization consists of three levels of P fertilizer, namely $100 \mathrm{~kg}$ SP-36 per ha (F3), $50 \mathrm{~kg}$ SP-36 per ha (F2) and without P fertilizer (F1).

The result of this study shows that the prediction model of cadmium content on carrot, leek, and stringbean based on cadmium, $\mathrm{pH}$, electricity power, and land organic $\mathrm{C}$ content cannot be revealed in this study since the cadmium content cannot be detected by AAS. Moreover, the cadmium content on carrot, leek, and string bean planted on four soil types and given different doses of P Fertilizer are under the standar set up by FAO/WHO $(<0,05-$ $01 \mathrm{mg} \mathrm{kg}^{-1}$ ).
\end{abstract}

Keywords: Cadmium,vegetables, soil type, P fertilizer

\section{PENDAHULUAN}

Kadmium merupakan salah satu logam berat yang terdapat dalam kerak bumi. Kadmium banyak dimanfaatkan oleh manusia dalam proses produksi logam seperti seng, timah hitam, dan tembaga, dengan tujuan utama untuk mencegah terjadi korosi yang berlebihan.
Selain berada pada logam, kadmium juga banyak ditemukan dalam rokok dan produk-produk pertanian, jika dikonsumsi dapat mengakibatkan kerusakkan pada ginjal, paru-paru, dan tulang (Corrosiondoctors, 2008; Alloway and Ayres, 1993; Slamet, 2002). Oleh karena itu dampak 
Charly: kandungan kadmium di dalam wortel, bawang prei dan buncis yang ditanam pada tanah berbahan induk kapur dan volkanik dengan dosis pupuk p yang berbeda

negatif dari kadmium perlu segera ditangani.

Penanganan dampak negatif kadmium yang telah dilakukan adalah dengan adanya penetapan toleransi asupan harian kadmium oleh Program Bersama Standar Makanan FAO (Food Agriculture Organisation) / WHO (World Health Organisation) (Joint FAO/WHO Food Standard Program), untuk perempuan dewasa adalah $60 \mu \mathrm{g}$ hari $^{-1}$ dan untuk pria dewasa adalah $70 \mu \mathrm{g}$ hari 1. Dalam produk pertanian juga ditetapkan tingkat maksimum kandungan logam berat dan batas toleransi konsumsi harian logam berat, khususnya untuk sayuran ditetapkan sebesar $0,05 \mathrm{mg} \mathrm{kg}^{-1}$ sampai $0,1 \mathrm{mg} \mathrm{kg}^{-1}$ berat basah hasil (Codex Alementarius Commission, 2001; Corrosion-doctors, Didownload June 23, 2008).

Setiap jenis sayuran mempunyai kepekaan penyerapan kadmium yang berbeda-beda. Kepekaan penyerapan kadmium sayuran dibagi ke dalam 3 kelompok yaitu sayuran yang mempunyai kepekaan tinggi (wortel, bawang putih, bayam, kentang, dll), kepekaan sedang (bawang prei, cabe, brokoli, bawang merah, tomat, dll) dan kepekaan rendah (buncis, jamur, kentang, dll) (National Kadmium Minimisation Committee. 2003). Kadmium yang diserap sayuransayuran tersebut berasal dari dalam tanah.

Secara alami, kadmium merupakan logam berat yang walaupun dalam jumlah sedikit selalu ditemukan dalam semua jenis tanah. Jadi tanah merupakan sumber utama kadmium yang diakumulasi oleh bahan makanan (Wagner, 1993). Ketersediaan kadmium di dalam tanah yang pHnya $<7$ (seperti pada tanah-tanah yang berasal dari bahan Volkanik atau tanah pada daerah yang curah hujannya tinggi) akan lebih tinggi daripada ketersediannya di dalam tanah yang pHnya > 7 (seperti tanah yang berasal dari bahan induk batu Kapur atau tanah yang berada pada daerah yang curah hujannya rendah) (Wiliam and David, 1973). Umumnya kadmium bersifat immobile di dalam tanah pertanian, namun demikian ketersediaan kadmium dalam tanah pertanian dapat meningkat ketika adanya modifikasi lingkungan tanah seperti perubahan $\mathrm{pH}$, kandungan bahan organik tanah dan pemberian pupuk $\mathrm{P}$.

Pupuk $\mathrm{P}$ mengandung kadmium dengan jumlah yang bervariasi menurut 
Charly: kandungan kadmium di dalam wortel, bawang prei dan buncis yang ditanam pada tanah berbahan induk kapur dan volkanik dengan dosis pupuk p yang berbeda

persen $\mathrm{P}_{2} \mathrm{O}_{5}$ dari pupuk $\mathrm{P}$ yang diberikan. Semakin tinggi persen $\mathrm{P}_{2} \mathrm{O}_{5}$, makin tinggi pula kadar kadmium di dalam pupuk $\mathrm{P}$ tersebut (Mermut, et al., 1996; Schroeder and Balassa; 1963). Dengan demikian, jika pupuk $\mathrm{P}$ diberikan ke dalam tanah, jumlah kadmium di dalam tanah akan meningkat dan selanjutnya diakumulasi di dalam tanaman dan hasilnya (Schroeder and Balassa; 1963; National Kadmium Minimisation Committee; 2003).

Informasi tentang kadmium tersebut di atas perlu diketahui oleh semua pihak. Namun, sejauh ini hanya negara-negara maju seperti Jepang, Canada, Australia, Amerika Serikat dan negara-negara Eropa Barat saja yang telah secara sadar menetapkan level maksimum kadmium di dalam produk pertanian dan bahan makanan (Codex Alementarius Commission, 2001; National Kadmium Minimisation Committee. 2003), sedangkan di Indonesia, perhatian mengenai pencemaran bahan makanan (hasil pertanian) oleh kadmium masih sangat rendah dan lebih banyak masih dalam taraf penelitian-penelitian. Khusus untuk Provinsi Nusa Tenggara Timur (NTT), belum terdapat informasi yang memadai mengenai kandungan kadmium dalam bahan pangan dan produk pertanian.

Berdasarkan uraian di atas, maka penelitian tentang "Kandungan Kadmium di dalam Wortel, Bawang Prei dan Buncis yang Ditanam Pada Tanah Berbahan Induk Kapur dan Volkanik Dengan Dosis Pupuk P yang Berbeda" perlu dilakukan.

\section{METODE PENELITIAN}

\section{Tempat dan waktu}

Penelitian dilakukan di kelurahan Naimata, Kota Kupang pada lahan milik warga, yang dilaksankan pada bulan November 2009 sampai April 2010.

\section{Pelaksanaan Penelitian}

Pelaksanaan penelitian meliputi Pengambilan tanah, Analisis awal (tanah dan pupuk) Persiapan media tanam, Aplikasi pemupukan, Persemaian dan penanaman, Pemeliharaan, Pemasangan ajir, Pengambilan sampel tanaman, Analisis sampel tanaman.

\section{Rancangan penelitian}

Percobaan pot ini menggunakan rancangan dasar Rancangan Acak Kelompok (RAK), dan merupakan percobaan faktorial dengan 3 faktor, yaitu faktor jenis tanaman, jenis tanah dan dosis pupuk. Level dari masing-masing faktor tersebut adalah: 
Charly: kandungan kadmium di dalam wortel, bawang prei dan buncis yang ditanam pada tanah berbahan induk kapur dan volkanik dengan dosis pupuk p yang berbeda

1. Jenis tanaman terdiri dari tiga level: Wortel (C1), Bawang Prei (C2) dan Buncis (C3).

2. Jenis tanah terdiri dari empat level yaitu tanah jenis Andosol Nduaria (S1), Mollisol Fatumnasi (S2), Vertisol Oesao (S3) dan Mollisol Baumata (S4).

3. Pemupukan terdiri dari tiga level pupuk P yaitu $100 \mathrm{~kg}$ SP-36 per ha, (F3), $50 \mathrm{~kg}$ SP-36 per ha (F2) dan tanpa pupuk $\mathrm{P}(\mathrm{F} 1)$.

Setiap satuan percobaan akan terdapat 3 ulangan dan diletakkan di lahan penanaman. Jadi akan ada 108 sampel tanaman (dari 3 jenis tanaman $x 4$ jenis tanah $\times 3$ dosis pupuk $\times 3$ ulangan = 108 satuan percobaan).

\section{Analisi statistik}

Data yang terkumpul diuji beda nyata berdasarkan sidik ragam. Perbedaan antar dua level faktor dilakukan uji t; sedangkan perbedaan antar lebih dari satu level faktor tunggal atau interaksi anatar faktor dilakukan dengan uji DMRT. Semua uji statistik dilakukan pada derajad beda nyata 5\%. Di samping itu, dilakukan pula pemodelan dengan analisis regresi dan korelasi untuk memprediksi kandungan $\mathrm{Cd}$ di dalam bagian tanaman yang dapat dimakan berdasarkan beberapa kandungan $\mathrm{Cd}$ tanah, $\mathrm{pH}$ tanah, kandungan $\mathrm{C}$ organik tanah, dan konduktifitas listrik tanah.

Kandungan $\mathrm{Cd}$ di dalam tanaman yang ditanam di masing-masing jenis tanah dibandingkan dengan batasan maksimum kandungan $\mathrm{Cd}$ yang disyaratkan oleh FAO dan WHO untuk mengetahui apakah tanaman yang ditanam di masing masing jenis tanah dan yang diberi pupuk mengandung $\mathrm{Cd}$ dalam batas maksimum yang ditetapkan oleh FAO dan WHO tersebut.

\section{Hasil dan Pembahasan}

Kandungan Kadmium di dalam Sayuran yang Ditanam pada Empat Jenis Tanah dengan Dosis Pupuk P yang Berbeda.

Hasil analisis laboratorium menunjukkan bahwa kandungan kadmium di dalam sayuran wortel, bawang prei dan buncis tidak dapat terdeteksi oleh AAS (Atomic Absorbtion System, Shimadzu AA_6650) yang mempunyai kemampuan mendeteksi kadmium hingga 1,00E-03 $\mathrm{mg} \mathrm{kg}^{-1}$ dan hal ini berarti kadmium yang ada di dalam sayuran berada di bawah ambang batas maksimum kandungan kadmium 
Charly: kandungan kadmium di dalam wortel, bawang prei dan buncis yang ditanam pada tanah berbahan induk kapur dan volkanik dengan dosis pupuk p yang berbeda

yang diperbolehkan oleh WHO/FAO.

Mengacu pada hal tersebut, maka dalam penelitian ini tidaklah perlu untuk membuat model prediksi kandungan kadmium di dalam tanaman berdasarkan sifat tanah seperti kandungan kadmium tanah, pH tanah, daya hantar listrik (DHL) dan kandungan $\mathrm{C}$ organik tanah.

Kandungan kadmium di dalam sayuran yang ditanam pada jenis tanah berbeda dan diberi pupuk $\mathrm{P}$ dengan dosis berbedapun sangat rendah sehingga tidak dapat dideteksi oleh AAS (<1,00E-03 mg $\mathrm{kg}^{-1}$ ) (Tabel 4.3). Rendahnya kandungan kadmium di dalam bagian sayuran ini sangat besar kemungkinan berhubungan dengan rendahnya kandungan kadmium di dalam tanah dan pupuk SP-36 (untuk semua jenis tanah) dan total kadmium di dalam tanah itu sendiri.
Pupuk P yang digunakan memberikan sumbangan kadmium yang sangat rendah ke dalam tanah, yakni sebesar 0,146 $\mathrm{mg} \mathrm{kg}^{-1}$, ditambah kadar kadmium yang rendah di dalam tanah yakni sebesar 0,0959 $\mathrm{mg} \mathrm{kg}^{-1}$ (Tabel 4.1), menyebabkan total kadmium yang ada di dalam tanahpun rendah. Rendahnya total kadmium di dalam tanah ini mempengaruhi rendahnya kadmium yang dapat diserap oleh sayuran yang ditanam (Tabel 4.2). Keadaan yang sama juga ditunjukan oleh wortel, bawang prei dan buncis yang dikonsumsi oleh masyarakat kota Kupang. Hasil analisi awal yang telah dilakukan menunjukan bahwa ketiga jenis sayuran tersebut (yang diambil dari pasar Impres Kupang) mengandung kadmium di bawah ambang batas toleransi yang ditetapkan $\mathrm{FAO} / \mathrm{WHO}$ (Tabel 4.3).

Tabel 4.3 Kandungan kadmium ( $\mathrm{mg} \mathrm{kg}^{-1}$ ) di dalam tiga jenis sayuran yang diambil di pasar Impres Kupang (batas kepekaan AAS 1,00E-03 $\mathrm{mg} \mathrm{kg}^{-1} ; \mathrm{R}^{2}$ absorbsi AAS = 0,998)

\begin{tabular}{ll}
\hline Jenis Sayur & Kandungan Kadmium \\
\hline Wortel & $<1,0 \mathrm{E}-03$ \\
Bawang Prei & $<1,0 \mathrm{E}-03$ \\
Buncis & $<1,0 \mathrm{E}-03$ \\
\hline
\end{tabular}

Analisis awal kandungan kadmium di dalam sayuran yang diambil dari pasar Impres, bertujuan agar dapat menjadi pembanding bagi sayuran yang ditanam ketika penelitian dilakukan. Sayuran yang diambil dari pasar Impres ini belum diketahui perlakuan yang diterapkan terhadap tanaman tersebut oleh para 
Charly: kandungan kadmium di dalam wortel, bawang prei dan buncis yang ditanam pada tanah berbahan induk kapur dan volkanik dengan dosis pupuk p yang berbeda

petani, baik itu jenis maupun dosis pupuk yang digunakan. Penjelasan mengenai kandungan kadmium yang rendah di dalam sayuran dari pasar ini, dapat dipaparkan berdasarkan hasil penelitian yang dilakukan, karena telah jelas diketahui perlakuan-perlakuan yang dilakukan.

\section{Kadmium di dalam buncis}

Buncis yang ditanam pada beberapa jenis tanah dengan dosis pupuk $\mathrm{P}$ yang berbeda mengandung kadmium yang rendah (di bawah ambang batas toleransi) disebabkan karena beberapa hal:

1. Tanah. Kandungan kadmium di dalam tanah yang digunakan sebagai media tanam rendah (Tabel 4.1). Tanah Molisol Baumata dan Vertisol Oesao mempunyai kandungan kadmium yang paling rendah yakni sebesar 1,00E-03 $\mathrm{mg} \mathrm{kg}{ }^{-1}$, kemudian diikuti oleh tanah Molisol Fatumnasi yakni sebesar $3,55 \mathrm{E}-02 \mathrm{mg} \mathrm{kg}^{-1}$ dan yang tertinggi kandungan kadmiumnya adalah pada tanah Andosol Nduaria Ende yakni sebesar 9,59E-02 mg kg-1. Rendahnya kandungan kadmium di dalam tanah ini, menyebabkan kadmium yang dapat diserap oleh buncispun rendah (Wiliam and David, 1973).
2. Pupuk. Kandungan kadmium di dalam pupuk $\mathrm{P}$ yang digunakan rendah, yakni sebesar 1.46E-01 mg kg-1 (Tabel 4.1). Rendahnya kandungan kadmium di dalam pupuk $\mathrm{P}$ yang digunakan ini, menyebabkan semakin rendah pula kadmium yang dapat diserap oleh buncis (Schroeder and Balassa; 1963; National Cadmium Minimisation Committee; 2003). Rendahnya kandungan kadmium di dalam sayuran, juga disebabkan karena baru sekali ini tanah-tanah tersebut diberi pupuk $\mathrm{P}, \quad$ sehingga akumulasi kadmium di dalam tanah rendah. Akumulasi kadmium yang rendah di dalam tanah ini, berpengaruh pada rendahnya kadmium yang dapat diserap tanaman (Wood dan Westfall, 2009).

3. $\mathrm{pH}$. $\mathrm{pH}$ tanah tempat penanaman sayuran ini mempengaruhi tinggi rendahnya kadmium yang tersedia bagi tanaman. Semakin tinggi $\mathrm{pH}$ tanah, maka kandungan kadmium di dalam tanahpun rendah, sehingga kadmium kadmium kurang tersedia bagi tanaman (Wiliam and David, 1973).

4. Sayuran. Buncis merupakan jenis sayuran yang mempunyai kepekaan 
Charly: kandungan kadmium di dalam wortel, bawang prei dan buncis yang ditanam pada tanah berbahan induk kapur dan volkanik dengan dosis pupuk p yang berbeda

rendah di dalam menyerap kadmium

(National Kadmium Minimisation

Committee. 2003). Rendahnya

kemampuan buncis di dalam

menyerap, ditambah rendahnya

kandungan kadmium di dalam tanah

dan pupuk menyebabkan kadmium

yang dapat diserap oleh buncispun rendah.

\section{Kadmium di dalam bawang prei}

Kandungan kadmium di dalam bawang prei yang ditanamn beberapa jenis tanah dengan dosis pupuk $\mathrm{P}$ yang berbeda rendah (di bawah ambang batas toleransi), disebabkan karena beberapa hal:

1. Tanah. Dari hasil analisis awal yang telah dilakukan (Tabel 4.1), diketahui bahwa tanah-tanah yang digunakan sebagai media tanam mengandung kadmium dalam jumlah yang rendah. Kadmium yang bersifat imobil ini, jika berada dalam jumlah yang rendah maka menyebabkan rendah pula kemampuan penyerapan bawang prei (Wiliam and David, 1973).

2. Pupuk. Pupuk P mengandung kadmium dalam jumlah yang bervariasi menurut persen $\mathrm{P}_{2} \mathrm{O}_{5}$ dari pupuk tersebut, dimana semakin tinggi persen $\mathrm{P}_{2} \mathrm{O}_{5}$, maka semakin tinggi pula kadar kadmium (Mermut, et al., 1996; Schroeder and Balassa; 1963). Kandungan kadmium di dalam pupuk $\mathrm{P}$ yang digunakan dalam penelitian ini rendah, yakni sebesar 1.46E-01 $\mathrm{mg} \mathrm{kg}^{-1}$ (Tabel 4.1). Rendahnya kandungan kadmium di dalam pupuk $\mathrm{P}$ yang digunakan ini, menyebabkan semakin rendah pula kadmium yang dapat diserap oleh bawang prei, selain itu tanah yang digunakan sebagai media tanam belum pernah menggunakan pupuk $\mathrm{P}$ sebelumnya sehingga terhindar dari akumulasi kadmium (Wood dan Westfall, 2009).

3. $\mathrm{pH}$. $\mathrm{pH}$ tanah tempat penanaman sayuran mempengaruhi rendahnya kadmium yang diserap tanaman. Semakin tinggi $\mathrm{pH}$ tanah, maka kandungan kadmium di dalam tanahpun rendah, sehingga menghambat penyerapan kadmium oleh tanaman (Wiliam and David, 1973).

4. Sayuran. Bawang prei merupakan jenis sayuran yang mempunyai kepekaan dalam menyerap kadmium yang tergolong sedang (National 
Charly: kandungan kadmium di dalam wortel, bawang prei dan buncis yang ditanam pada tanah berbahan induk kapur dan volkanik dengan dosis pupuk p yang berbeda

Kadmium Minimisation Committee. 2003). Keadaan seperti ini, ditambah rendahnya kandungan kadmium pada tanah dan pupuk $\mathrm{P}$ yang digunakan menyebabkan kadmium yang dapat diserap oleh sayuran rendah.

\section{Kandungan kadmium di dalam wortel}

Hasil analisis menunjukan dua kondisi, yakni kandungan kadmium yang tinggi dan rendah di dalam tanaman wortel. Kandungan kadmium di dalam wortel tinggi, pada tanah Andosol Nduarai dengan pemberian dosis pupuk $\mathrm{P}$ $100 \mathrm{~kg} \mathrm{ha}^{-1}$, keadaan ini tidak berarti dapat menggambarkan tingkat bahaya kadmium di dalam wortel tersebut. Hal ini dikarenakan, perlakuan yang terdiri dari 3 ulangan ini, hanya mampu dianalisis satu ulangan saja (karena rusaknya AAS).

Kandungan kadmium di dalam wortel yang rendah (di bawah ambang batas toleransi) disebabkan karena beberapa hal: Hasil analisi awal menunjukan bahwa total kadmium rendah pada tanah-tanah yang digunakan sebagai media tanam, akibatnya tanaman wortel hanya mampu menyerap kadmium dalam jumlah yang rendah (Wiliam and David, 1973). Pupuk $\mathrm{P}$ yang diberikan akan mempengaruhi konsentrasi kadmium di dalam tanah. Semakin tinggi kandungan kadmium di dalam pupuk P, maka semakin tinggi pula kadmium yang berada di dalam tanah (Schroeder and Balassa; 1963; National Kadmium Minimisation Committee; 2003). Pupuk P yang digunakan dalam penelitian ini mengandung kadmium dalam jumlah yang rendah, yakni sebesar 1.46E-01 mg $\mathrm{kg}^{-1}$ (Tabel 4.1). Rendahnya kandungan kadmium di dalam pupuk $P$ yang digunakan ini, menyebabkan semakin rendah pula kadmium yang dapat diserap oleh Wortel (Schroeder and Balassa; 1963; National Kadmium Minimisation Committee; 2003). Pengaruh lain dari pupuk $\mathrm{P}$ terhadap rendahnya serapan kadmium oleh tanaman wortel adalah karena tidak adanya akumulasi kadmium dari pupuk $\mathrm{P}$ di dalam tanah yang digunakan sebagai media tanam (Wood dan Westfall, 2009).

Penyerapan kadmium oleh wortel juga dipengaruhi oleh $\mathrm{pH}$ tanah. Tanahtanah dengan $\mathrm{pH}$ yang tinggi, mempengaruhi rendahnya penyerapan kadmium tanaman, sedangkan tanahtanah dengan $\mathrm{pH}$ rendah, mempengaruhi tingginya penyerapan kadmium oleh 
Charly: kandungan kadmium di dalam wortel, bawang prei dan buncis yang ditanam pada tanah berbahan induk kapur dan volkanik dengan dosis pupuk p yang berbeda

tanaman (Wiliam and David, 1973). Wortel merupakan jenis sayuran yang memiliki kepekaan yang tinggi di dalam menyerap kadmium (National Kadmium Minimisation Committee. 2003), namun karena rendahnya kadmium di dalam tanah dan pupuk $\mathrm{P}$ yang digunakan menyebabkan kadmium yang dapat diserap oleh wortelpun rendah.

\section{Kesimpulan}

1. Model prediksi kandungan kadmium tanaman wortel, bawang prei dan buncis berdasarkan kandungan kadmium, pH, Daya Hantar Listrik, dan kandungan $\mathrm{C}$ organik tanah tidak dapat dilakukan dalam penelitian ini karena kandungan kadmium tanaman tidak dapat terdeteksi oleh AAS.

2. Kandungan kadmium di dalam wortel, bawang prei dan buncis yang ditanam pada ke empat jenis tanah dan diberi dosis pupuk $\mathrm{P}$ yang berbeda berada di bawah batas ketetapan FAO/WHO $(<0,05-01 \mathrm{mg}$ $\left.\mathrm{kg}^{-1}\right)$.

\section{Ucapan Terima Kasih}

Pada kesempatan ini penulis ingin mengucapkan terima kasih kepada semua pihak yang telah membantu dengan caranya masing-masing dalam melengkapi tulisan ini.

\section{DAFTAR PUSTAKA}

Adams, M. L., F. J. Zhao, S. P. McGrath, F. A. Nicholson, and B. J. Chambers. 2004. Predicting Cadmium Concentrations in Wheat and Barley Grain Using Soil Properties. J. Environ. Qual. 33:532-541.

Adriano, D.C. 1986. Trace Element in the environment. Springer-Verlag. New York.

Alloway, B.J. and D.C. Ayres.1993. Chemical principles of environmental pollution. Blackie academic \& Professional. London. UK.

Anosimous. 2002. Dasar-dasar ilmu tanah. Faperta_Undana. Kupang.

Cheng, W., G. Zhang, H. Yao, W. Wu, M. Xu. 2006. Genotypic and environmental variation in cadmium, chromium, arsenic, nickel, and lead concentration in rice grains. J. Zhejiang Univ. Science B. 7:565-571.

Codex Alimentarius Commission. 2001. Coments submitted on the draft guideline level and proposed draft maximum level for cadmium. Codex Committee on Food Additives and 
Charly: kandungan kadmium di dalam wortel, bawang prei dan buncis yang ditanam pada tanah berbahan induk kapur dan volkanik dengan dosis pupuk p yang berbeda

Contaminants. Agenda item 16d, National Cadmium Minimisation CX/FAC 01/28. Thirty Third Session, Committee. 2003. Managing cadmium 12 - 16 March, 2001. The Hague, The Netherlands. Joint FAO/WHO Food Standards Program. Rome, Italy.

Darmono, 1995. Logam dalam sistem biologi makhluk hidup. Penerbit UI Press. Jakarta.

Gomes, K. A. dan Gomes, A.A. 1995.

Prosedur statistik untuk penelitian pertanian. Penerbit UI Press. Jakarta.

Laboratorium MIPA. 2010. Analisis kadmium pada tanah. FMIPA-Undana. Kupang.

Mench, M.J. 1998. Cadmium availability to plants in relation to major long-term changes in agronomy system. Agrcult. Ecosyst. Environ. 67: 175-187.

Mermut, A.R., J.C. Jain, L. Song, R. Kerrich, L. Kozak, and S, Jana. 1996. Trace element concentration of selected soils and fertilizers in Saskatchewan, Canada. J. Environ. Qual. 25: 845-853.

Moshin, Y. 2006. Kadmium. http://www.chem-is-try.org./tabel periodik/ kadmium/ didownload 19 Febuari 2010. in vegetables. VEGEnotes. July 2003. www. Cadmium-management.org.au. Didownload 23 Juni, 2008. Horticulture Australia. Sidney, NSW 2000, Australia.

Pratiwi, D., Jurniana, T., Kurniawati., K. Umi. 2008. Unsur kadmium. http://himdikafkipuntan.blogspot.com/2 008/05/cadmium.html. Didownload Febuari 2010.

Senn, A. and P. Milham. 2007. Managing cadmium in vegetables. New South Wales Department of Primary Industries.

http://www.dpi.nsw.gov.au/agriculture/ho rticulture/vegetables/soil/cadmium didownload 19 Juni, 2008.

Slamet, J.S. 2002. Kesehatan lingkungan. Gadjah Mada University Press. Yogyakarta.

Wu, J., W.A. Norvel, D.G. Hopkins, and R.M. Welch. 2002. Spatial variability of grain cadmium and soil characteristics in a durum wheat field. Soil sci. Soc. Am. J. 66:268-275. 